Aporte al conocimiento de la diversidad poblacional en El Carmen y la banda sur del río Negro, Nordpatagonia (1779-1852)

Beatriz del Valle Moldes, Jorge Raúl Entraigas Relaciones, 46(2), e026, julio-diciembre 2021 ISSN 1852-1479 | https://doi.org/10.24215/18521479e026 https://revistas.unlp.edu.ar/relaciones ISSN 0325-2221 (versión impresa) Sociedad Argentina de Antropología (SAA) Buenos Aires I Argentina

NOTA

\title{
APORTE AL CONOCIMIENTO DE LA DIVERSIDAD POBLACIONAL EN EL CARMEN Y LA BANDA SUR DEL RÍO NEGRO, NORDPATAGONIA (1779-1852)
}

\author{
CONTRIBUTION TO KNOWLEDGE OF DIVERSITY POPULATION IN EL CARMEN \\ AND THE SOUTHERN BAND OF RÍO NEGRO, NORDPATAGONIA (1779-1852)
}

Beatriz del Valle Moldes* y Jorge Raúl Entraigas**

Fecha de recepción: 15 de enero de 2021

Fecha de aceptación: 22 de junio de 2021

\section{INTRODUCCIÓN}

El presente es un aporte al conocimiento de la problemática poblacional en el bajo curso del río Negro, en un diálogo interdisciplinario entre la historia, antropología y demografía, durante la época tardo colonial y la formación del estado nacional (1779-1852), a partir de los registros parroquiales cuya importancia radica en que reflejan parcialmente la diversidad poblacional. Con este propósito se analizaron sistemáticamente las actas matrimoniales realizadas entre 1780 y 1852 en la "capilla del fuerte de Ntra. Sra. del Carmen en el río Negro de la costa oriental llamada Patagónica". Aportan, además, una mirada cotidiana y la red de interrelaciones sociales enmarcadas en las relaciones de frontera, destacándose el rol de la Iglesia y de la Guarnición del fuerte como intermediarios culturales, habiendo tenido la última un papel demográfico relevante.

\footnotetext{
* Se desempeñó en el Centro de Investigaciones Científicas/Dirección de Estudios Rionegrinos y como docente regular en el Centro Regional Zona Atlántica (Universidad Nacional del Comahue). E-mail: beamentraigas@gmail.com

** Se desempeñó en el Archivo Histórico provincial, Centro de Investigaciones Científicas/Dirección de Estudios Rionegrinos y como docente. E-mail: jrentraigas@ gmail.com
} 
Complementan las fuentes mencionadas, el análisis de algunas variables cuantitativas procedentes de la etapa preestadística, además de la visión cualitativa aportada por viajeros.

\section{UNA FRONTERA SINGULAR}

El tema de la frontera fue tratado mediante variados enfoques, aunque prevaleció una connotación fuertemente política vinculada con la necesidad estatal de defender territorios en disputa (Ratto y Lagos 2011). Desde el punto de vista histórico y etnohistórico, en ambientes académicos argentinos y chilenos, a partir de la década de 1980, surgió un nuevo paradigma de "frontera" centrado en un espacio dinámico, flexible, horizontal, de interrelaciones e intercambios entre distintos sectores socioétnicos (Mandrini 1992; Ratto 1994; Pedrota y Lantieri 2015; de Jong 2016; Farberman y Ratto 2017; Lucaioli y Nacuzzi 2010, entre otros). Estudios que inicialmente se vincularon con la formación de un espacio mercantil en el área pampeano nordpatagónica, que fue acompañado de un proceso de complejización social en ciertos grupos que dio lugar a importantes jefaturas (Salinas Grandes y Las Manzanas), aunque el resto mantuvo la propiedad fusión/fisión típica de las sociedades segmentales. Los trabajos mencionados renovaron los estudios fronterizos e impulsaron la formación de un campo fructífero que reconoce la estrecha relación de la historia indígena con la historia nacional, que incluye variados procesos con continuidades, cambios y rupturas en las relaciones interétnicas fronterizas a partir de la etapa colonial, en tanto que con los gobiernos independientes surgieron asentamientos y prestaciones militares gestándose una particular interrelación entre la sociedad indígena y las autoridades mediante la formulación de pactos y tratados denominado el "negocio pacífico de indios" (Ratto 1994). Sistema practicado en varios puntos de la frontera pampeano patagónica que transformó las condiciones de actuación indígena (Literas y Barbuto 2015).

En el río Negro, mediante el proyecto borbónico, a partir del siglo XVIII comenzó un proceso de diálogo multiétnico cotidiano entre hispano-criollos, indígenas y esclavos africanos o libertos originándose una sociedad diversa culturalmente. Esta política implementada por Francisco de Viedma consistió en acuerdos e intercambios políticos, económicos, sociales y culturales que durante un siglo facilitó la supervivencia del Fuerte del Carmen con escasos conflictos. En estos procesos la iglesia tuvo una singular actuación al igual que la milicia. De acuerdo con Nicoletti y Malvestitti (2009) con el objetivo de evangelizar, la iglesia también trataba de incorporar súbditos a la corona primero y luego como “argentinos”, en tanto que los indígenas, según D’Orbigny (1945, II: 809), solo aceptaban el cristianismo "cuando tenían alguna cosa que conseguir de los padres".

\section{LA FORMACIÓN DE UN PECULIAR ESPACIO HISPANO-CRIOLLO Y UNA PERIFERIA SOCIOÉTNICA DIVERSIFICADA}

Los primeros españoles venidos por "contratas" (Apoland 1970), en 1779, se establecieron desde el litoral atlántico hasta San Javier, a unos $60 \mathrm{~km}$ de la desembocadura del río Negro; por el norte llegaron hasta San Blas y por el sur, hasta las mesetas adyacentes. Los indígenas permitieron a los españoles la ocupación de ese espacio según la tradición oral y escrita en fuentes hispano-criollas (Ratto 2008), posteriormente ratificada en un tratado de paz (Vignatti 1972), en tanto ellos se ubicaron estacionalmente entre sus instalaciones.

Inicialmente, los "cristianos" conformaron un aislado grupo socioeconómico, político, religioso, lingüístico y cultural hegemónico, en comunicación diaria con vecinos más numerosos, étnicamente diferentes, poseedores de un territorio autónomo y de un modo de vida propio, de quienes dependían, por lo que debieron hacer acuerdos políticos, familiares, y de intercambio 
de bienes (Ratto 2008). Completan la diversificación étnica, la población afro dependiente de la "blanca" y cristianizada.

Las condiciones ambientales, la vida cotidiana, situaciones de vecindad y ciertas circunstancias históricas impulsaron fluidas relaciones socioeconómicas en este espacio fronterizo. Finalmente, la hegemonía estatal terminó con el libre movimiento entre estos mundos, ocasionando conflictos, discriminación, marginación y pérdidas.

El espacio tuvo una ocupación diferencial. Sobre la margen norte del río Negro los españoles trasladaron el fuerte (previamente construido en la margen opuesta), símbolo de la soberanía hispánica, aunque ofrecía una débil protección. A su amparo residieron las autoridades, la mayoría de los pobladores y se refugiaron los labradores dispersos ante los escasos ataques indígenas. El río constituyó una fluida vía de comunicación interior mediante pequeños puertos (San Javier y el de la salina) y el más importante, el de El Carmen, donde llegaban embarcaciones y mercancías de diversas procedencias, incluidos esclavos (Bustos 1993; Cassano 2011).

En la banda sur, los humedales y las periódicas inundaciones promovieron las actividades agropecuarias en mayor escala que en la norte. En un principio, los pobladores cruzaban diariamente, posteriormente se establecieron de manera dispersa. La feracidad del valle en el límite oeste de la ocupación fue utilizada para llevar la hacienda del rey (Alioto 2011) y en 1782 se estableció el fuerte San Javier para su protección, surgiendo otro punto de encuentro interétnico, periférico, de gran importancia en el siglo siguiente. Desde allí mantenían una controlada comunicación intercultural, más que una defensa importante. Se compartían las mismas condiciones materiales de vida, se buscaba información, contactos o intercambios con el "otro cultural" a la vez que se instalaba un lugar netamente multicultural, con una gran diversidad lingüística. Meca de los naturalistas y expedicionarios que iniciaban sus viajes a las mesetas o cordillera.

Fuera del límite de la ocupación hispano-criolla, a unos 10 km del fuerte de San Javier, surgió San Gabriel o Potrero Grande, un lugar utilizado para establecer toldos y practicar actividades productivas, muy visible con Yanquetruz. En el mapa de Díaz y Heusser figura como "campo de Chingoleo", rodeado de ocupaciones "cristianas" (1865 Archivo Histórico de Río Negro) ${ }^{1}$, posteriormente se establecieron los Linares (Claraz 1988).

\section{MOVILIDAD ESPACIAL Y PARENTESCO}

Algunos estudios de frontera destacaron la movilidad espacial de la población, una variable que, desde el punto de vista demográfico, tiene la capacidad de modificar la dinámica poblacional al afectar la composición y el crecimiento, además imposibilita su cuantificación y conocer su trayectoria (Vinuesa 1987). En estos casos, la sociedad suele estar mestizada debido a las relaciones entre variados sectores socio étnicos.

Celestino Almeida y Ortelli (2012) cuestionan el tradicional esquema de oposición entre indígenas y no indígenas, como así también entre los grupos sometidos al estado y los autónomos, puesto que entre ambos existió la circulación de población que dio lugar a intensas relaciones interétnicas que incluyen formas de protección, colaboración, convivencia, mestizajes, intercambios, conflictos y violencia, dando lugar a complejos procesos de adaptación y re significación o reelaboración de las identidades. Para estas autoras, la movilidad permitía entrar y salir, comunicarse con cautivos, fugitivos, vagabundos, desertores y malhechores, o intérpretes y secretarios, algunos de los cuales actuaron como bisagras entre ambos mundos. En tal sentido, Wilde (2003) sostiene que aun las actividades ilegales creaban dinámicos espacios de sociabilidad, siendo la fuga y la movilidad estrategias básicas ante un estado débil.

Por su parte, Literas (2016) expresa que en los asentamientos en torno a núcleos urbanos y fortines se generaron nuevas formas de identificación y acción que produjeron situaciones de 
interacción e interdependencia entre actores con heterogéneas trayectorias y pertenencias culturales que favorecieron el parentesco interétnico. Procesos, según Literas, elaborados con sentido de supervivencia, adaptación y búsqueda de espacios de autonomía en el contexto histórico de avance estatal de los territorios que ocupaban en el siglo XIX, lo que no significa ignorar la violencia física y simbólica.

A nivel local, Davis (2017), en un estudio sobre Carmen de Patagones (1856-1870), destaca al parentesco que mediante la reciprocidad estructuró alianzas entre indígenas y criollos que permitieron mantener la paz local dentro de un contexto general de alta conflictividad, donde estos lazos pesaban más que las pertenencias étnicas.

\section{ALGUNOS INDICADORES POBLACIONALES DE EL CARMEN (1779-1852)}

En el periodo propuesto, las escasas informaciones demográficas pertenecen a fuentes pre estadísticas (padrones, recuentos globales de población, censos) y a estudios históricos generales que hacen referencias sobre la población "blanca" y afro del asentamiento. Al margen quedaron la población militar y la indígena autónoma. Otras fuentes son los registros parroquiales en donde se anotaban las prácticas asociadas con los hechos vitales (nupcialidad, fecundidad y mortalidad). Motivos que dificultan las comparaciones.

Uno de los primeros registros fue el padrón de 1788 (Museo y Archivo Emma Nozzi. MAEM) que reconoció 86 unidades domésticas, entre las cuales 55 eran vecinos (en su mayoría labradores castellanos y gallegos), y 30 forasteros de otras procedencias dedicados a oficios varios. La actividad principal fue la agrícola, le seguía el intercambio ejercido en las redituables pulperías (diecisiete en total), muy concurridas por los indígenas (D’Orbigny 1945), como en la pampa (Mandrini 2006), o en el nordeste, sitios también de intercambio de información y búsqueda de parejas (D’Orbigny 1945; Wilde 2003).

El padrón citado indica que un $62 \%$ de los vecinos estaba casado, además había $22 \%$ de solteros y $16 \%$ de viudos. Entre los forasteros predominaban los solteros (60\%). En relación con la distribución por sexo, se destaca que la mujer estuvo ausente entre abril y octubre de 1779. Estas comenzaron a llegar con las remesas de inmigrantes (Apoland 1970). Por consiguiente, hubo un notorio predominio masculino que influyó en la búsqueda y formación de parejas (nupcialidad), de allí la importancia de conocer la relación hombre/mujer (IM) como indicador de contactos interculturales.

Un análisis del IM disponible en algunas fuentes arrojó los siguientes resultados: en 1816 era de 146,6 entre los hispano-criollos, algo menor entre los esclavos (120) (Rey et al. 1987). En el padrón de 1821 (MAEN), se registraron 471 habitantes, cuyo IM era de 144, pero si se toma en cuenta la población económicamente activa (PEA), entre 15 y 60 años, el IM fue de 173,3, tendencia que se incrementó posteriormente. Estos valores demuestran un desequilibrio en la relación hombre/mujer, con una mayor cantidad de varones, especialmente en edades activas (PEA), indicios de una fuerte inmigración de hombres solos, tendencia que continuó posteriormente. El envío de presidiarios y soldados incrementaba la masculinidad al igual que la presencia de desertores y vagabundos.

Por ende, la escasez femenina hispano-criolla, junto con algunas pautas culturales, dificultaban la búsqueda de pareja e influían en la reproducción y estabilidad familiar. Para contrarrestar esta escasez hay indicios de su búsqueda entre la población flotante del poblado, o en los asentamientos periféricos ya mencionados, tal como lo señala D’Orbigny (1945).

En la sociedad indígena, generalmente, las uniones se hacían con el consentimiento de las partes a través del rapto u otras prácticas, las que en algunos linajes destacados fueron cambiando ante el contacto con el blanco (Bechis 1994). 
Por consiguiente, en un ambiente de frontera, existieron uniones que seguían las pautas étnicas tradicionales, pero también hubo interrelación entre personas con distintas pertenencias culturales. Sin embargo, la formalidad cristiana apoyada desde el poder trató de imponerse a todos los sectores socioétnicos. Quedaron al margen de la cuantificación que se presenta las uniones consensuales fuera de la iglesia, aunque algunas podrían ser detectadas indirectamente.

\section{Normativas y testimonios de las actas parroquiales}

Al comienzo de la colonización americana, la corona española pretendía la "limpieza de sangre" para lo cual promovía el control de la población mediante los registros parroquiales; por ende, la iglesia y el estado impulsaron un orden social basado en tres grupos básicos: blancos (cristianos), indios, negros (en adelante, afro) y numerosas castas mestizas, clasificación adoptada en demografía histórica. Era una manera de regular la familia, la sexualidad y el parentesco. Sin embargo, esta rígida estructura fue corroída cuando las castas furtivamente lograban un cambio, ante lo cual se dictó una Real Cedula (1795) que permitía a una persona ser blanca a los efectos legales mediante alguna prestación (Ripodas de Ardanaz 1977).

En el siglo XVIII, el aspecto religioso fue relevante en las reformas borbónicas (Wilde 2003), por lo que, el matrimonio cristiano configuró la base de la organización social. Como sacramento había sido regulado por el Concilio de Trento (al igual que los archivos), y también por encíclicas y el derecho canónico. Una Real Pragmática (1776) adaptada a la diversidad de "Indias" en 1778 legisló sobre las aptitudes para el matrimonio, la elección de los cónyuges y el domicilio, trámites, tipos de uniones, ritos, impedimentos, dispensas y anulaciones (Ripodas Ardanaz 1977); algunas pautas persistieron en el periodo tratado como las referidas a las milicias y la clasificación socio étnica, importantes temáticas no incluidas en la presente nota.

Las fuentes elegidas, por tener una serie continua, han sido analizadas cuali y cuantitativamente. Comenzaron en 1780, al contrario de las de bautismo que datan desde 1804. En la parroquia de El Carmen, los primeros curas, mercedarios jubilados venidos del norte, no llevaron libros separados por etnia (blanco, indios, negros) para registrar los sacramentos, aunque esta condición era anotada en cada acta. Tal vez, por experiencia misional, conocían la debilidad de esas categorías ante el mestizaje.

Como los contrayentes eran adultos, tuvieron cierto protagonismo en la aceptación, aun cuando hubieran sido presionados socialmente. Cumpliendo las normas, cada acta reflejaba la interrelación de varias personas con el fin de concretar los pasos reglamentados: compromiso, amonestaciones, celebración en la iglesia, velación, registros escritos (protocolo, cuerpo y escatocolo), todo lo cual implica ciertas interacciones o negociaciones (Martínez 1991; Siegrist 2016), que aún desconocidas, sugieren la situación de cada contrayente a la vez que dejan entrever procesos intra e interculturales. Un caso es el matrimonio del Comandante del Fuerte, coronel Francisco Crespo, autorizado por sus superiores, cuyo testigo (ausente) fue el gobernador Juan M. de Rosas, representado por una paraguaya (Acta 230/1832). Otro caso trata sobre un militar y una cautiva rescatada "tenida" en los campos de un baqueano (Acta 372/1844), o, la unión de un "moreno" con la hija del "indio platero" (Acta 409/1847). En estas ceremonias indudablemente participaron intermediarios, no siempre conocidos, que colaboraron con el cura, una figura generalmente respetada en la época y con apoyo de las autoridades.

Otros ejemplos, más intraétnicos, son las excepciones y dispensas que indicaban situaciones críticas "para el alma", contexto social conflictivo, ausencia de autoridades, o un alto grado de endogamia especialmente entre los primeros pobladores españoles.

A continuación se presenta una síntesis del análisis realizado (1780-1852) en el que se tuvieron en cuenta las principales etapas cronológicas de la región y los grupos étnicos según la nomenclatura derivada de las fuentes (tabla 1). 
Relaciones de la Sociedad Argentina de Antropología 46 (2), julio-diciembre 2021: 725-735

Tabla 1. Matrimonios realizados en la parroquia Nuestra Señora del Carmen en el río Negro entre 1780 y 1852 por etapas cronológicas y porcentaje según clasificación socio étnica

\begin{tabular}{|c|c|c|c|c|c|}
\hline \multirow{2}{*}{ Etapas } & \multicolumn{5}{|c|}{ PORCENTAJE } \\
\cline { 2 - 6 } & Blancos & Afro & Interétnicos & Indígenas & s/d \\
\hline $1780-1814$ & 73 & 14 & 10 & 0 & 2 \\
\hline $1815-1832$ & 78 & 10 & 12 & 0 & 0 \\
\hline $1833-1852$ & 46 & 17 & 12 & 7 & 18 \\
\hline
\end{tabular}

\section{El período tardo-colonial (1780-1814)}

Debido al aislamiento y la mentalidad de los pioneros, el movimiento revolucionario tuvo escasa repercusión y ante una sublevación pasaron a depender de los realistas de Montevideo hasta 1814. Constituyó una etapa de escasez, y de adaptación al nuevo hábitat y a la convivencia con los indígenas. Carente del auxilio de las autoridades coloniales, apenas pudieron subsistir. Después de 1810, la anarquía reinante entre realistas y patriotas, junto con las amenazas de ataques indígenas empobrecieron la comarca.

El núcleo inicial, hegemónico, se mantuvo mediante matrimonios realizados entre las principales familias (73\%), dándose casos de uniones endogámicas o, eventualmente, la unión con algún criollo o extranjero. Quedaban disponibles las viudas.

Desde 1784 se registran uniones interétnicas entre cristianos y pardos, o indígenas (10\%), con la particularidad de que el personal subalterno de la Guarnición del fuerte (soldados, cabos o sargentos, generalmente mestizos, afro o indígenas guaraníes) debía obtener permiso para contraer nupcias según la Pragmática de 1778, y lo hacía con viudas españolas o indígenas de Misiones, bodas que se incrementaron con el tiempo. Entre 1808 y 1812 las autorizaciones militares procedieron del comandante de Montevideo. No se registraron matrimonios entre indígenas patagónicos dada su autonomía, sin embargo, algunas mujeres indígenas locales se unieron con algún miembro de los grupos mencionados.

La categoría afro (14\%) estaba integrada por personas procedentes de distintos lugares de África, de Brasil, o nacidos en la comarca. Por lo general realizaban tareas domésticas, artesanales o trabajaban en los campos o salina dependiendo del grupo hegemónico.

\section{Etapa transicional (1815-1832)}

Alejados los intentos sediciosos hispánicos como el de 1817, la nueva organización del país produjo un cambio importante desde 1820 al pasar a depender de la provincia de Buenos Aires. A nivel local se comenzaron a organizar las instituciones a cargo de autoridades federales (justicia de paz, educación, comunicaciones, finanzas y representantes a la legislatura provincial). La economía se basó en el auge del saladero, la ganadería y el comercio. A causa de la guerra con Brasil, se incrementó el movimiento comercial de bienes y de esclavos debido a la acción de piratas y corsarios. Si bien la mayoría de los esclavos arribados fueron distribuidos en otras regiones, un importante número permaneció en la comarca repartidos entre la guarnición del fuerte (soldados) o como libertos bajo el patronato de los vecinos, por lo tanto, se produjo un significativo cambio en la composición social según Cassano (2011).

Las conflictivas relaciones con los nativos, originadas por la presión de realistas chilenos 
aliados a indígenas, asolaron distintas áreas. La prosperidad obtenida en la comarca peligró al ser atacada por una coalición nordpatagónica, rápidamente desarticulada, que permitió recuperar parte del botín (1829). El cuadro general de beligerancia impulsó la actuación de Rosas.

En relación con las uniones, se mantuvo la tendencia anterior con leves aumentos en hispano-criollos (78\%) e interétnicos (12\%), y ligeras bajas entre la población afro (10\%), que a pesar del importante aporte ingresado, pocos se casaron.

Se produjeron nuevos ingresos de inmigrantes, procedentes del resto del territorio nacional y también de países limítrofes y europeos. Para las mujeres de la elite local, contraer nupcias con algún rico comerciante o militar graduado significaba un ascenso social (Rey et al. 1987).

\section{La etapa rosista (1833-1852)}

Durante esta etapa tuvo lugar la avanzada de Pacheco al río Negro, vanguardia del ejército de Rosas, que impulsó la circulación de personas (milicias, prisioneros, cautivos rescatados, chinas tomadas), y de bienes (los vivanderos llevaban víveres para el ejército y traían cueros). Posteriores incursiones indígenas procedentes del área pampeana fueron controladas desde fuertes o fortines ubicados en la banda norte.

La comarca tuvo un periodo de relativa paz debido a la política basada en el "negocio pacífico" instrumentada por Rosas. Aumentaron las estancias criollas y también la permanencia de los nativos a lo largo de la banda sur con motivo de los acuerdos y la recepción de las raciones, intensificándose el comercio interétnico. Al final de esta etapa se instaló Yanquetruz.

La ausencia de información sobre etnicidad motivó la habilitación de la categoría "sin datos" (s/d) para numerosos matrimonios, de los que tampoco se conocen la procedencia o progenitores. Entre 1839 y 1842 no hay actas, el párroco Pedro Luque fue reemplazado por Julián Faramiñán quien en el libro de matrimonios escribió: "he recibido este libro de casamiento en el estado en que se halla" (9 de diciembre de 1842, acta 336). Queda pendiente averiguar la naturaleza de este importante subregistro.

Barral (2004) sostiene que durante el rosismo los curas debían tener un papel de agente político, en tanto que Ratto (2002) sostiene que Rosas le dio mucha importancia a la Iglesia y aspiraba tener curas federales, para eso solicitó al gobernador Balcarce un capellán federal bien remunerado para Bahía Blanca y Patagones.

Es la etapa más prolongada y con mayor cantidad de matrimonios (239). Con respecto a la anterior, disminuyeron las uniones entre criollos, españoles y europeos (46\%), aunque persistieron casos de endogamia. Hacia 1850 se registraron casamientos por poder entre militares cuyas futuras esposas se encontraban en Bahía Blanca.

Aumentaron los matrimonios de origen afro (17\%), especialmente entre 1835-39, que podría atribuirse al aumento de este colectivo durante la guerra de corso con Brasil (Cassano 2011) o a la permanencia de soldados una vez finalizada la campaña de 1833. Rosas obtuvo autorización para que los individuos de su división se casaran con las cautivas liberadas, matrimonios a ser confirmados por algún sacerdote (Saldías 1967). Habría que indagar si se aplicó en el río Negro. Acerca del objetivo de estas bodas para este sector, Cassano (2011) sugiere que pudo ser una muestra de disciplinamiento, o una estrategia de ascenso social y legitimación de su descendencia.

Continúa la tendencia de uniones interétnicas (12\%), entre criollos o milicianos con viudas, cautivas rescatadas, pardas, libertas y criollas. Continuaron las uniones entre indígenas y "blancos".

La novedad de la etapa fue el matrimonio entre indígenas cristianos locales (7\%), registrados por primera vez entre 1845-49, lo que significó un pequeño cambio sociocultural, fruto de la acción del cura-federal-y sus allegados. Una cuestión pendiente es el elevado aumento de las uniones sin datos (18\%); podría responder a un problema de las fuentes, de interpretación, o a un proceso 
de blanqueamiento decidido para algunos casos (por ejemplo contrayente con padres indígenas), pero en su mayoría se trataba de pobladores afro, por consiguiente, la Iglesia contribuiría a un importante cambio socio étnico.

La trayectoria de Blas Ureña es una muestra de las interrelaciones sociales del periodo tratado. Era uno de los hijos del pionero Juan de Ureña. En 1794, Blas contrajo matrimonio con María Román, española (Acta 31), en tanto que un hermano de María se casó con "una india pampa" en 1801 (Acta 67). Estas tempranas relaciones interétnicas derivaron en extensos parentescos ya que a fines del siglo XVIII la familia Ureña-Román entroncaba con sus vecinos indígenas con quienes mantuvo buenas relaciones saliendo de testigo en varios matrimonios de indígenas con criollas, y también con pobladores españoles del establecimiento (Guerrero -León, Román-Baler). Tal vez estas vinculaciones le sirvieron para "rescatar o comprar", en 1804, a un indiecito "auca" de un año, cautivado en guerra, bautizado con el nombre de Manuel de la Asunción, cuyos sus padrinos fueron Blas Ureña y María Román su mujer. La pareja se hizo cargo del niño actuando como padres; cuando Manuel contrajo matrimonio con Rosa Velasco en 1832, en el acta figura Blas Ureña como padre (Acta 233). En el mismo año, Manuel fue padre de Feliciana Ureña, quien en 1853 contrajo matrimonio con Miguel Linares. Asimismo, las vinculaciones sociales y económicas los llevaron a entablar relaciones con la población de origen afro al obtener en patronato a dos varones y una mujer (Cassano 2011) a quienes dieron su apellido al ser bautizados. En definitiva, fue una familia que tuvo vinculaciones parentales con diferentes etnias que coexistieron en este espacio fronterizo. Estrategias que también siguieron otros pobladores españoles, prácticas no aceptadas ampliamente por el núcleo inicialmente establecido. ${ }^{2}$

Cuando en 1851 José María Bulnes Yanquetruz bautizó a uno de sus hijos fue registrado en el libro como cacique (Acta 38), al igual que cuando él mismo recibió el bautismo en 1852 con el nombre de Francisco Santiago y el cura agregó "mantuve Yanquetruz" (Acta 27); su padrino fue el comandante Francisco Formantin de Vivoar (sic). Estaba instalado en San Gabriel junto con sus familiares (Varela y Manara 2007), asimismo, fue testigo de sacramentos oficiados en la parroquia, con lo cual afianzaba una red de protección, reciprocidad y parentesco. Sin embargo, tuvo una actitud ambivalente en relación con lo religioso ya que Tomas Guevara indica que visitó la cueva de Cura Malal para ser reconocido como un guerrero valiente (Casamiquela 1998), estas ambigüedades simbólicas, para Wilde (2003) pueden ser propias de espacios fronterizos.

\section{CONSIDERACIONES FINALES}

Las fuentes analizadas indican que la población se caracterizó por ser diversificada socioétnicamente, con un alto índice de masculinidad y una elevada movilidad espacial, variables que afectaron la nupcialidad. Si bien se considera que la información pertenece al sector hegemónico cristiano, reflejan una población de frontera,conformada en procesos aun poco conocidos. Estas características, unidas a pautas culturales, impulsaron la interrelación socio étnica y el parentesco, destacándose en este proceso la acción de la Iglesia que con sus normas, ceremonias y participación del clero fue intermediaria entre contrayentes, familiares, y testigos, cuyo resultado fue la formación de redes de alianza y parentesco real o simbólico entre distintos grupos étnicos. A su vez, la reglamentación de la guarnición del fuerte facilitó las relaciones interétnicas, especialmente entre los sectores subalternos.

Entre 1780 y 1820, al aislado núcleo poblacional hegemónico, hispano-criollo y sus descendientes, centrado en El Carmen, se incorporaron inmigrantes provincianos, extranjeros, indígenas (de origen guaraní) y una visible población afro (entre soldados, esclavos o libertos). En un contexto de penurias económicas y algunos conflictos con los indígenas, los pioneros mantuvieron uniones entre sí, en algunos casos endogámicas. Los matrimonios entre pobladores afro, e interétnicos 
fueron poco numerosos, proviniendo sus esposas del colectivo afro o indígenas locales o procedente de las misiones guaraníticas.

A partir de 1820 los cambios institucionales y de jurisdicción impulsaron algunas modificaciones. En la banda sur se expandió la colonización hacia el noroeste, con la custodia del decaído fuerte de San Javier, creado en 1782; en sus cercanías surgió San Gabriel, otro lugar de asentamiento indígena y de relaciones interétnicas. En ambos lugares periféricos se estableció una población no cuantificable de indígenas, quienes participaron en la formación de parejas cristianas. Al final de la década, el próspero desarrollo económico obtenido fue malogrado por graves conflictos con los indígenas (1829).

Los nuevos aportes poblacionales, con predominio masculino en edades activas, arribaron libremente desde distintas procedencias, sin embargo, la migración forzada esclava fue significativa. Esta fue destinada a la alicaída guarnición del fuerte o se distribuyó entre el vecindario local bajo el patronato.

La tipología matrimonial socioétnica en general mantuvo la tendencia anterior con algunos cambios, como el aumento del predominio de los criollos (1820-1824) atribuible a la bonanza económica; baja en las uniones afro -aun cuando hubo un incremento de su colectivo-, y aumento en los interétnicos con las pautas del ciclo anterior.

Finalmente, durante la etapa rosista se produjeron importantes cambios en el contexto histórico, poblacional y cierta expansión territorial en la que convivieron grupos interétnicos. La escueta información de numerosas uniones impulsó la categoría de "s/d". Entre la población blanca se observó una disminución de casos y un aumento de las uniones afro (cuyo pico fue entre 1835-1841), seguramente producto de la liberación del patronato de quienes llegaron durante la etapa anterior o del establecimiento de soldados que quedaron de la campaña de 1833. Otro cambio operado es el matrimonio entre indígenas cristianos de la zona producto de la evangelización.

Al final del periodo estudiado, la diversidad socioétnica inicial en los registros parroquiales comenzó a diluirse, seguramente con conocimiento de Rosas, mediante el "blanqueamiento" de la población afro y de algunos indígenas. La Iglesia colaboró en este proceso y en la resultante formación de alianzas y parentesco real o simbólico entre los distintos grupos étnicos, contribuyendo al cambio sociocultural.

Fue una sociedad que, a pesar de los conflictos y contradicciones, logró adaptarse, mantener la paz, forjar una sociedad más abierta y convivir durante un siglo.

\section{AGRADECIMIENTOS}

A la Comisión Directiva de La Sociedad Argentina de Antropología por permitir la presentación de este trabajo, a los evaluadores que con sus precisas observaciones lo enriquecieron. A la informante Lía García Linares y al Ing. Adrián Henri por sus conocimientos sobre la zona. A la Prof. Evangelina Gil por su apoyo informático, a colegas, familiares y amigos quienes alentaron nuestra tarea.

\section{NOTAS}

1 En el mapa de 1865, sin topónimos, está la ubicación de Chingoleo. Sitio denominado Potrero Grande en otros mapas, al que Claraz identificó con San Gabriel. Mediante una informante que nació allí, en el campo de su familia, pudimos determinar que todos esos nombres se referían al mismo lugar, ubicado sobre el Meridiano V, separación entre Buenos Aires y Rio Negro.

2 En pleno siglo XX, un descendiente de una de estas familias, refiriéndose a sus antepasados, reseñó sus actividades y logros, con el comentario final de "lástima que se juntó con esos". Por otro lado, descendientes de algunas familias no reconocen sus ancestros indígenas o mestizos. 
Relaciones de la Sociedad Argentina de Antropología 46 (2), julio-diciembre 2021: 725-735

\section{REFERENCIAS BIBLIOGRÁFICAS}

Alioto, S. (2011). Indios y Ganado en la frontera. La ruta del río Negro (1750-1830). Rosario. Prohistoria Ediciones.

Apoland, J. A. (1970). Operativo Patagonia. Montevideo. Imprenta Letras.

Bechis, M. (1994). Matrimonio y política en la génesis de dos parcialidades mapuche durante el siglo XIX. Memoria Americana. Cuadernos de Etnohistoria 3: 41-62. Buenos Aires. FFLUBA.

Barral, M. E. (2004). Las parroquias rurales de Buenos Aires entre 1730 y 1820 . Andes $\mathrm{N}^{\circ} 15$. Salta. Universidad Nacional de Salta.

Bustos, J. (1993). Indios y blancos, sal y ganados más allá de la frontera. Patagones 1820-1830. Anuario IEHS, VIII. Tandil. UNICEN.

Casamiquela, R. (1998). En pos del Gualicho. Buenos Aires: Fondo Editorial Rionegrino.

Cassano, G. A. (2011). Guardianes de la frontera: La población negra del Carmen de Patagones durante la primera mitad del siglo XIX: una aproximación desde la antropología histórica. Tesis de Licenciatura inédita, Facultad de Filosofía y Letras, Universidad Nacional de Buenos Aires.

Celestino de Almeida, M. R. y S. Ortelli (2012). Atravesando fronteras. Circulación de población en los márgenes iberoamericanos. Siglos XVI-XIX (segunda parte), Nuevo Mundo Mundos Nuevos, Debates [En línea], [Consultado el 01 junio 2012] http://nuevomundo.revues.org/62628

Claraz, J. (1988). Diario de viaje de exploración al Chubut. 1865-1866. Buenos Aries. Editorial Marymar

Davies, G. (2017). El impacto de la política cacical en la frontera: las redes de parentesco y la estructura social de Carmen de Patagones, 1856-1879. Buenos Aires. Boletín del Instituto de Historia Argentina y Americana "Dr. Emilio Ravignani", № 46.

De Jong, I. (comp.) (2016). Diplomacia, malones y cautivos en la frontera sur, siglo XIX. Buenos Aires. Sociedad Argentina de Antropología.

D’Orbigny, A. (1945). Viaje a la América Meridional. Tomo III. Buenos Aires. Editorial Futuro.

Faberman, J. y S. Ratto (2017). Redes políticas y sociales en espacios de frontera, Buenos Aires. Boletín del Instituto de Historia Argentina y Americana "Dr. Emilio Ravignani". 46.

Literas, L. (2016). Armas, parentesco y tierra en la frontera. La tribu de Rondeau y los orígenes de Veinticinco de Mayo. En I. de Jong (comp.), Diplomacia, malones y cautivos en la frontera sur, siglo XIX. Miradas desde la antropología histórica: 263-327. Buenos Aires. Sociedad Argentina de Antropología.

Literas, L. y Barbuto, L. (2015). Política y liderazgo en las tribus de indios amigos de la frontera bonaerense (segunda mitad del siglo XIX). En XV Jornadas Interescuelas / Departamentos de Historia. Universidad Nacional de La Pampa, Santa Rosa La Pampa.

Lucaioli, C. y L. Nacuzzi (comps.) (2010). Fronteras. Espacios de interacción en las tierras bajas del sur de América. Buenos Aires, Sociedad Argentina de Antropología.

Mandrini, R. (1992). Indios y fronteras en el área pampeana (siglos XVI-XIX). Balance y perspectivas. ANUARIO IEHS 7: 59-72.

Mandrini, R. (2006). Desventuras y venturas de un gallego en el Buenos Aires de fines de la Colonia. Don 
Beatriz del Valle Moldes y J. R. Entraigas - Aporte al Conocimiento de La diversidad Poblacional ...

Blas Pedrosa. En R. Mandrini (ed.), Vivir entre dos mundos. Las fronteras del sur de la Argentina. Siglos XVIII-XIX: 43-72. Buenos Aires. Taurus.

Martínez, T. M. (1991). Paleografía y diplomática. Madrid, Universidad Nacional de Educación a Distancia.

Nicoletti, M. A. y M. Malvestitti (2009). Werkenalu dios ta ñi zungu / para llevar el mensaje de dios. Los catecismos en lengua indígena en el área territorial mapuche (s. XIX). Estudios Trasandinos: 5-27.

Pedrota, V. y S. Lantieri (dirs.) (2015). La frontera sur de Buenos Aires en la larga duración. Una perspectiva multidisciplinar. La Plata. AHPBA.

Ratto, S. (1994). Indios amigos e indios aliados. Orígenes del "Negocio Pacífico" en la provincia de Buenos Aires (1829-1832). Cuadernos del Instituto Ravignani. 5.

Ratto, S. (2002). Prácticas sociales indígenas en un espacio fronterizo. Revista de Historia Bonaerense $\mathrm{N}^{\circ}$ 24. Instituto Histórico de Morón.

Ratto, S. (2008). Allá lejos y hace tiempo. El Fuerte de Carmen de Patagones en la primera mitad del siglo XIX. Quinto Sol. No 8: 45-72.

Ratto, S. y M. Lagos (2011). El concepto de frontera interior: de la política a la historiografía. Entrepasados 36/37: 51-72.

Rey, H., J. Quiroga, B. Moldes de Entraigas, A. Peronja, G. N. Suárez, J. Entraigas, J. Bustos y E. Cardone (1987). Historia del Valle Inferior. Buenos Aires. Plus Ultra.

Ripodas Ardanaz, D. (1977). El matrimonio en Indias, realidad social y regulación jurídica. Buenos Aires. Fundación para la Educación, la Ciencia y la Cultura.

Saldías, A. (1967). Historia de la Confederación Argentina. Buenos Aires. Editorial Granda.

Siegrist, N. (2016). Dispensas y matrimonios secretos en Buenos Aires e Hispanoamérica. Siglo XVII. Revista Complutense de Historia de América 42: 41-71. http://dx.doi.org/10.5209/RCHA. 53710

Varela, G. y Manara, C. (2007). Liderazgos indígenas de la nordpatagonia frente a la política estatal: la renovación de estrategias (1850-1880). $1^{\circ}$ Congreso Latinoamericano de Historia Económica, $4^{\circ}$ Jornadas Uruguayas de Historia Económica, CLADHE I- IV JUHE, Montevideo, 5-7 de diciembre de 2007.

Vignatti, M. A. (1972). Un capítulo de etnohistoria nordpatagónica. José María Bulnes Yanquetruz. Investigaciones y Ensayos 13. Buenos Aires. Academia Nacional de la Historia.

Vinuesa, J. (ed.) (1987). Demografía, análisis y proyecciones. Madrid. Editorial Síntesis.

Wilde, G. (2003). Orden y ambigüedad en la formación territorial del río de la Plata a fines del siglo XVIII. Horizontes Antropológicos, Porto Alegre, ano 9, n. 19: 105-135. 
